\title{
Pesquisa
}

\section{TRATAMENTO HUMANIZADO AOS PORTADORES DE DIABETES}

\author{
Érika Maria Alves Moreira (1) \\ Daniele Silva Medeiros (2) \\ Edilânia Nunes de Araújo (3) \\ Adriana Maria Simião da Silva (4)
}

\section{Resumo}

Neste artigo, analisa-se a importância do tratamento humanizado aos portadores de diabetes. É interessante, a partir da compreensão das concepções acerca da humanização no atendimento em saúde, elaborar esta discussão que trata da qualidade da assistência prestada ao cliente diabético, considerando a susceptibilidade do mesmo, principalmente quando se depara com o desenvolvimento de complicações. Trata-se de uma revisão bibliográfica, na qual aspectos importantes sobre a humanização foram abordados, primando, preponderantemente pelos norteamentos necessários à efetivação da humanização no atendimento aos portadores de diabetes. Conclui-se, ao final do artigo, que para implantar um atendimento humanizado é preciso iniciar a discussão dessa temática durante a formação do profissional de saúde, de forma a prepará-lo para um desempenho pautado em valores que primem pelos aspectos essenciais ao ser humano, demonstrando, por meio das próprias atitudes, que tratar o próximo com igualdade e como ser humano, que possui direitos, história e expectativas, é realmente humanizar.

Palavras-chave: humanização, atendimento, diabetes 


\section{Introdução}

Através deste estudo, no qual se analisa a importância do tratamento humanizado aos portadores de diabetes, quer-se ampliar as discussões sob novos olhares reflexivos frente à adoção de posturas diferentes em relação ao tratamento de diabéticos, com possibilidades de um olha mais atento e humano por parte dos profissionais de saúde.

Deslandes (2004), tomando por base documentos oficiais sobre a humanização da atenção, faz questão de destacar que a concepção de humanização da atenção conforma-se como uma diretriz de trabalho, que aspira a uma nova "práxis" para a atenção à saúde. Assim, baseando-se na análise de tais documentos e corroborando o que afirma Deslandes, é que Martins (2003) conclui que tal inovação, de caráter processual e complexo, prevê mudanças que podem gerar insegurança e resistências por parte dos profissionais de saúde, já que não são passíveis de padronizações nem são generalizáveis, enfatizando a singularidade dos processos de atenção à saúde.

É interessante, a partir da compreensão das concepções acerca da humanização no atendimento em saúde, elaborar esta discussão que trata da qualidade da assistência prestada ao cliente diabético, considerando a susceptibilidade do mesmo, principalmente quando se depara com o desenvolvimento de complicações.

A justificativa para a produção de um estudo com foco na humanização no atendimento aos portadores de diabetes, é uma forma de, utilizando o exercício da pesquisa teórica, com base em estudiosos diversos, poder ter um maior embasamento da prática profissional em saúde e, mais especificamente, dos cuidados necessários aos portadores de diabetes, considerando ser este um assunto muitas vezes colocado em segundo plano.

Para a abordagem em questão, centraliza-se o presente artigo, na seguinte questão norteadora: que compreensão existe dos profissionais de saúde, acerca do tratamento humanizado aos portadores de diabetes? Para isso, é relevante que aspectos importantes sobre a humanização sejam abordados, primando, preponderantemente pelos norteamentos necessários à efetivação da humanização no atendimento aos portadores de diabetes.

Optou-se por embasar a pesquisa na revisão bibliográfica, quando o intuito é que se obtenha o aporte teórico necessário à elucidação do tema proposto no presente artigo. 


\section{A humanização das práticas em saúde}

Costuma-se falar sobre uma divisão clássica que tornam distintos um componente científico-tecnológico e um componente humanístico na prática da medicina. Para Schraber (1997), esse tipo de distinção acaba provocando uma hierarquização na qual se pressupõe a supremacia do componente científico-tecnológico em detrimento do humanístico, numa visão que não é somente dos profissionais de saúde, mas, da sociedade de uma forma geral.

A autora chama a atenção para o caráter interativo das práticas de saúde e para a particularidade de cada caso clínico, o que conforma uma dimensão da atenção à saúde que não pode ser inteiramente controlada e resolvida como estrita aplicação técnica de um saber de natureza científica (SCHRABER, 1997).

Entende-se que a intervenção técnica se articula verdadeiramente como um Cuidar quando o sentido da intervenção passa a ser não apenas o estado de saúde visado de antemão, nem somente a aplicação mecânica das tecnologias disponíveis para alcançar este estado, mas o exame da relação entre finalidades e meios e seu sentido prático, conforme um diálogo o mais simétrico possível entre profissionais e usuários dos serviços (AYRES, 2004).

É importante enfatizar que tem se apresentado como um grande desafio no dia a dia da atenção à saúde, a reflexão e a operação da dimensão prática que vai além dos objetos produzidos pelas tecnociências biomédicas. É importante que esteja incorporado de forma ativa, às finalidades e formas de atuação do projeto assistencial, das quais se transformam em sujeitos tanto os profissionais da saúde quanto os usuários dos serviços.

Quando se discorre sobre humanização do atendimento em saúde, é preciso estar atento sobre aquilo que acompanha o nosso cotidiano. A insatisfação da sociedade e a precariedade dos serviços em saúde é destaque na mídia diariamente. Os problemas vão desde a falta de leitos, exames, aparelhos quebrados, falta de vagas, mortes, erros médicos ao mau atendimento por conta de grosserias, indiferença, negligência. Ainda pesa sobre isso a insatisfação dos profisssionais de saúde, mal remunerados, sobrecarregados e, conseqüentemente, com a produtividade aquém do desejado.

Assim, como destaca Mandu (2004, p. 665), algumas questões são consideradas fundamentais na atenção predominante, dentre as quais podem ser destacadas: limitado acesso aos cuidados; manutenção de processos e tecnologias de trabalho homogeneizantes, desconsiderando a diversidade de condições, identidades, experiências e contextos de intersubjetividade; permanência da tradição autoritária, distanciada e hierarquizante nas interrelações entre profissionais e sujeitos, alvos dos cuidados em saúde, centrada em referências 
profissionais e em um modo científico de identificar, controlar e tratar problemas que exclui os saberes e as experiências diversos do outro pólo da relação.

O problema é que, quanto mais se "tecniciza" o setor de saúde, quanto mais máquinas se interpõem entre o profissional e o cliente, maior é a necessidade que essa relação seja humanizada (ISMAEL, 2002).

Ganong, citado por Casete e Correa (2005), coloca que humanizar significa reconhecer as pessoas que buscam nos serviços de saúde a resolução de suas necessidades de saúde, como sujeitos de direitos [...] é observar cada pessoa em sua individualidade, em suas necessidades específicas, ampliando as possibilidades para que possa exercer sua autonomia.

Para isso, destaca-se aqui a importância dos profissionais de saúde, que devem ver o paciente além da doença e tentar enxergar a necessidade de conforto que tem o indivíduo que chega em suas mãos, geralmente inseguro, frágil e que busca naquele atendimento, a solução de seus problemas.

Como bem destaca Ismael (2002), a arte de curar transcende o conhecimento científico e, por isso, prescinde do equilíbrio harmonioso entre o talento do profissional, sua formação e uma visão humanista do seu ofício, permeada por noções básicas de psicologia, que o ajudariam a separar a doença do doente.

\section{Diabetes: algumas considerações}

Estima-se que existam no Brasil cerca de 5 milhões de indivíduos com diabetes dos quais metade desconhece o diagnóstico, ou seja, a doença será identificada freqüentemente pelo aparecimento de uma de suas complicações. A prevalência de diabetes (numero de casos existentes em relação à população) nos indivíduos entre 30 e 70 anos de idade é de 7,6\%, semelhante à prevalência em vários países desenvolvidos. (MALERBY \& FRANCO, 1996).

O diabetes muda completamente a rotina de uma pessoa. São necessárias adaptações nos esquemas de alimentação, esporte, emprego... Se o diabético não estiver controlado e o trabalho envolver riscos, como locais elevados, maquinário pesado, etc., será preciso considerar a necessidade de uma troca por atividades menos perigosa. Por essa razão, é importante que todos os que convivam com o paciente (família, amigos, colegas de 
trabalho) conheçam a doença e saibam tratá-lo em momentos de crise. O apoio é fundamental e, em muitos casos, o auxílio psicológico de um profissional se faz necessário (RAMIRES, 1992).

Um dado alarmante sobre essa doença é que, no mundo, mais de 50\% dos indivíduos não têm conhecimento que têm diabetes, o que está custando à sociedade milhões de dólares no tratamento de muitas complicações graves que surgem do diabetes não diagnosticado ou não devidamente tratado (cegueira, insuficiência renal, doenças nervosas, amputação de membros e doenças cardiovasculares). Em alguns países este número pode chegar a $80 \%$. É importante enfatizar que o diabetes é a quarta maior causa global de mortes por doença. Estudo do Ministério da Saúde e da Sociedade Brasileira de Diabetes Estudo sobre a doença no Brasil detectou que cerca de 50\% das pessoas não conheciam o diagnóstico.

Esse desconhecimento da doença pode ser a porta de entrada para uma diversidade de outros problemas de saúde, fazendo com que fiquem ameaçados órgãos, nervos e vasos sanguíneos, por isso, o melhor caminho é livrar-se do risco e saber que a prevenção é de suma importante e a forma de conseguir isso, é tendo o tratamento adequado e dando continuidade a ele, para que a doença não evolua e não haja perigo de complicações característicos da doença.

\section{O tratamento humanizado aos portadores de diabetes}

Têm sido percebidas pouca eficácia nas técnicas convencionais de tratamento aos portadores de diabetes, como por exemplo, orientações para redução de peso através de dietas. Os métodos convencionais de tratamento do diabetes, incluindo orientação de uma dieta de redução de peso, geralmente, não têm sido eficazes.

Vê-se, muitas vezes, que o êxito acontece quando entra em cena a grande força de vontade dos indivíduos portadores da doença, que demonstram compromisso em adotar um novo estilo de vida, incluindo, aí, novos hábitos dietéticos para a vida toda.

Mas, é preciso que ineficácia de alguns métodos funcionem como um sinal de alerta para que profissionais de saúde procurem mudar sua postura e, partirem para a busca de novas formas de se relacionarem com doentes em condições crônicas, como é o caso dos 
diabéticos. É preciso que o portador da doença compreenda que é possível manter a qualidade de vida, apesar do diabetes e para isso, não basta apenas o tratamento medicamentoso, já que, como afirma Mandu (2004), a valorização da inter-subjetividade por parte dos profissionais para agirem de acordo com a bagagem cultural dos indivíduos, dando-lhe liberdade e incentivo para encontrarem modos apropriados de manterem sua qualidade de vida.

Silva (2000) através de estudos, chegou a conclusão que as pessoas diabéticas constroem seus próprios caminhos para lidarem com as condições crônicas, buscando saberes além dos saberes científicos. O método de discussão e reflexão (caracterizado como educação em saúde) em grupos formados por profissionais de enfermagem e pessoas em condições crônicas tem sido uma das formas que tem dado resultado na manutenção da qualidade de vida das pessoas em condições crônicas.

A educação em saúde para as pessoas diabéticas precisa configurar-se em um processo contínuo, abrangente, de modo a incluir não apenas informações sobre o tratamento médico tradicional, mas também fatores ambientais, maneiras de compreender e de lidar com o diabetes e, sobretudo, proporcionar espaço apropriado para as relações de acolhimento, criação de vínculos entre usuários e profissionais da saúde e proporcionar maior autonomia a essas pessoas de modo a conviverem com o diabetes de uma forma saudável. Para que isso aconteça, as instituições de saúde necessitam mudar as estratégias tradicionais de cuidado às pessoas de diabéticos, e que, provavelmente, muitos serão diagnosticados somente quando alguma complicação se manifestar (BRASIL, 1989).

A humanização do atendimento aos portadores de diabetes abrangeria, fundamentalmente, aquelas iniciativas que apontam para a democratização das relações que envolvam o atendimento; o maior diálogo e melhoria da comunicação entre profissional de saúde e paciente; o reconhecimento dos direitos do paciente, de sua subjetividade e referências culturais, ou ainda, o reconhecimento das expectativas de profissionais e pacientes como sujeitos do processo terapêutico. Em suma, o desafio da humanização diria respeito à possibilidade de se construir uma nova ordem relacional, pautada no reconhecimento da alteridade e no diálogo"(DERLANDES, 2004).

Assunção et al. (2001) conduziram um estudo para avaliar a estrutura, o processo e o resultado do cuidado do paciente diabético atendido em nível primário de atenção à saúde em Pelotas, Estado do Rio Grande do Sul; A avaliação do resultado mostrou uma estrutura precária dos postos de saúde referente à disponibilidade recomendada de suprimentos mínimos necessários para o atendimento aos diabéticos. O processo de cuidado consistia 
exclusivamente no atendimento médico, somente $50 \%$ dos pacientes faziam controle glicêmico e os dados mostraram ainda baixa adesão à dieta e aos exercícios físicos e um mecanismo de monitorização deficiente. Esses dados vêm confirmar nossa crença de que as instituições de saúde necessitam urgentemente renovar seu sistema de assistência.

A atuação de alguns profissionais de saúde ocorre de forma desarticulada das políticas de saúde, gerando problemas como a desumanização da assistência, a falta de comprometimento, a baixa resolutividade das ações, além da ausência da oferta de um cardápio que garanta o acesso e o acolhimento dos usuários (Moretto, 2000). Por outro lado, os profissionais vivenciam uma crise referente a sua realização e satisfação, enquanto profissionais e cidadãos. Deste modo, se faz necessário a responsabilização destes pela qualidade da assistência que ofertam neste "trabalho vivo em ato dependente", colocando seus conhecimentos como opções tecnológicas, produzindo ações eficazes a serviço dos usuários e de seus problemas (Merhy, 1997b).

Lembrando o pensamento de Merhy: não será suficiente corrigirmos procedimentos organizacionais e financeiros das instituições de saúde, se não houver mudança no modo de relacionamento entre os trabalhadores de saúde e o seu principal objeto de trabalho - a vida e o sofrimento dos usuários (Merhy et al., 1997).

Para Mehry et al. (1997), criar vínculos entre trabalhadores e usuários implica prover espaços de relações de tal maneira a haver sensibilização com o sofrimento do usuário; é construir um processo de troca entre o usuário e o trabalhador que possa resultar na autonomia do usuário; é tornar-se referência para o usuário.

Alguns textos mostram a importância da humanização, confrontando-a com o desenvolvimento tecnológico na sociedade atual, alegando que ele distancia e modifica a relação profissional/paciente. Há que se considerar, porém, que a falta de recursos tecnológicos, quando estes são necessários, também pode representar fator de estresse e de conflito entre profissionais e usuários e, por conseguinte, desumanizando o cuidado.

É importante enfatizar que o tratamento do diabetes não se resume ao médico prescrever o medicamento e a dieta, mas deve-se estender no que toca a parte psicológica, social e econômica do paciente. Prescrever uma dieta com alimentos que a pessoa diabética não poderá comprar fará com que este não siga a dieta, prejudicando o tratamento.

Sabemos que o atendimento humanizado inicia-se já na admissão do cliente, quando há preocupação com o tempo de espera, com a distribuição de senhas e colocação de cadeiras para que possa aguardar com mais conforto. A humanização mostra-se na forma 
como acolhemos o cliente no setor, sendo-lhe fornecidas informações sobre normas e rotinas da instituição de saúde; explicações no momento da realização de procedimentos e mesmo na aparência do profissional da área de saúde, pois, quando nos observam, verificam se somos cuidadores de nós mesmos, capazes de cuidar deles.

Entretanto, é importante considerar que mudar uma cultura é algo bastante complexo, principalmente no que se refere à humanização, a qual envolve fatores subjetivos como sensibilidade e doação, perpassando, ainda, por questões psicológicas, como as experiências já vivenciadas.

Portanto, para implantar um atendimento humanizado é preciso iniciar a discussão dessa temática durante a formação do profissional de saúde, de forma a prepará-lo para um desempenho pautado em valores que primem pelos aspectos essenciais ao ser humano, demonstrando, por meio das próprias atitudes, que tratar o próximo com igualdade e como ser humano, que possui direitos, história e expectativas, é realmente humanizar.

\section{Considerações Finais}

É importante compreender que embora muitas dificuldades existam dificuldades, é possível realizar procedimentos de forma humana, e assim, o profissional de saúde estará demonstrando que não está ali somente cumprindo e executando tarefas, mas, com a vida de pessoas em suas mãos, e, também, tem a responsabilidade de preservar-lhes a dignidade.

A desumanização se faz fortemente presente no momento em que o paciente parece perder sua personalidade, percebendo-se anônimo, sendo apenas um número, uma doença, um dado estatístico, um procedimento, quando sua história, seus sentimentos e suas expectativas são deixadas de lado. Dirigir-se ao cliente chamando-o pelo nome, explicandolhe os passos do procedimento a ser realizado e demonstrando interesse em sua história é instituir, no relacionamento profissional-cliente, o representante máximo da humanização: o diálogo.

O ser humano diabético, pelas complicações que fazem parte de sua patologia, encontra-se mais suscetível, muitas vezes dominado pela ansiedade, medos e expectativas de recuperação ou incapacidade. A amenização desse estado emocional é possível com a prestação de um cuidado humanizado que priorize o ouvir, o dialogar, o compreender e o 
orientar, não priorizando um tecnicismo exclusivo. É preciso evitar a mecanização, para que se possa falar realmente em tratamento humanizado em saúde.

\section{Referências}

AYRES, J.R.C.M. Sujeito, intersubjetividade e práticas de saúde. Ciência e Saúde Coletiva, 2001.

ASSUNÇÃO, M.C.F. et al. Atenção primária em diabetes no sul do Brasil: estrutura, processo e resultado. Revista da Saúde Pública, São Paulo, v. 35, n. 1, p. 88-95, fev. 2001.

BRASIL. Instituto Nacional de Assistência Médica e Previdência Social - Inamps. Estudo multicêntrico sobre a prevalência do diabetes mellitus no Brasil: resultados. Brasília, 1989.

BRASIL. Ministério da Saúde. Manual de diabetes mellitus. 2 ed. Brasília, 1993.

CASETE JC, Corrêa AK. Humanização do atendimento em saúde: conhecimento veiculado na literatura brasileira de enfermagem. Rev Latino-Am Enf 2005.

DESLANDES S.F. Análise do discurso oficial sobre a humanização da assistência hospitalar. Ciên Saúde Coletiva 2004

ISMAEL JC. O médico e o paciente: breve história de uma relação delicada. São Paulo: T. A. Queiroz; 2002.

MALERBY, D. A. \& Franco, L. J. Diabetes Care,15:1509-1516,1996.

MANDÚ ENT. Intersubjetividade na qualificação do cuidado em saúde. Rev Latino-Am Enf 2004.

MERHY E.E.; ONOCCKO, R. (Org.). Práxis em Salud: um desafio para lo publico. Textos em espanõl y português. São Paulo: Hucitec, 1997.

MERHY, E.E. Em busca da qualidade dos serviços de saúde: os serviços de porta aberta para a saúde e o modelo tecnológico em defesa da vida (ou como aproveitar os ruídos do cotidiano dos serviços de saúde e colegiadamente reorganizar o processo de trabalho na busca da qualidade das ações de saúde). In: CECÍLIO, L. C. O. (Org.). Inventando a mudança na saúde. São Paulo: Hucitec, 1997

SCHRAIBER, L.B . No encontro da técnica com a ética: o exercício de julgar e decidir no cotidiano do trabalho em medicina. Interface: Comunicação, Saúde, Educação, 1997.

SILVA, D.M.G.V da. Narrativas do viver com diabetes mellitus: experiências pessoais e culturais. 2000. Tese (Doutorado) - Curso de Pós-graduação em Enfermagem. Universidade Federal de Santa Catarina, Florianópolis, 2000. 
Sobre as autoras:

(1) Érika Maria Alves Moreira é Bióloga e Especialista em Administração Hospitalar pela Universidade Regional do Cariri - URCA.

E-mail: erika-bio@hotmail.com;

(2) Daniele Silva Medeiros é Enfermeira e Especialista em Administração Hospitalar pela Universidade Regional do Cariri - URCA.

(3) Edilânia Nunes de Araújo é Bióloga e Especialista em Administração Hospitalar pela Universidade Regional do Cariri - URCA.

(4) Adriana Maria Simião da Silva é Mestre e Professora da Universidade Regional do Cariri URCA.

E-mail: Adriana_simiao@hotmail.com

\section{Como citar este artigo (Formato ISO):}

MOREIRA, Érika M. A.; MEDEIROS, Daniele S.; ARAÚJO, Edilânia N. e SILVA, Adriana M. S. Tratamento humanizado aos portadores de diabetes. Id on Line Revista de Psicologia - Edição Especial Educação e Saúde, set. 2009, vol.1, no.9, p.58-67. ISSN 1981-1189. 